OLENNAISTA ON

TULLA YMMÄRRETYKSI JA

OLLA VUOROVAIKUTUKSESSA.

\title{
Yliopiston eetosta etsimässä
}

\section{Kokeiluja ja kokemuksia monitieteisestä altistumisesta aikakauden polttaville kysymyksille}

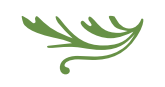

Tampereen yliopistossa järjestettiin turvapaikanhakijoille avoin kurssi, jonka taustalla oli huoli nyky-yliopiston eetoksesta ja kysymys siitä, miten yliopisto toteuttaa kasvatusvastuutaan maapalloisten kriisien ja niiden paikallisten vaikutusten edessä. Tavoite oli pohtia kriittisesti maahanmuuton kysymyksiä monitieteisissä ryhmissä ja kyseenalaistaa monikulttuuristumista ja työelämän muutosta koskevia valtavirtadiskursseja.

TURVAPAIKANHAKIJAMÄÄRÄN NOPEA lisääntyminen Euroopassa vuonna 2015 sai aikaan keskustelun, jossa maahanmuuttajien osallistumista koulutukseen alettiin arvioida uudelleen. Jotkin suomalaisetkin korkeakoulut reagoivat tilanteeseen ja tarjosivat erilaisia ratkaisuja, esimerkiksi suomalaiseen yhteiskuntaan tutustuttavia kursseja (ks. Vaarala ym. 2017). Useat ratkaisut olivat kuitenkin lyhytaikaisia, ja nyttemmin monet lupaavatkin aloitteet ovat unohtuneet.
Erityisesti korkeakoulukelpoisten ja korkeakoulutettujen maahanmuuttajien pääsy koulutusta vastaavaan työhön tai jatko-opintoihin on edelleen hankalaa. (Kyhä 2012; Käyhkö 2017, Lepola 2017.)

Toteutimme keväällä 2017 Tampereen yliopistossa kasvatustieteen, sosiaalityön ja kielentutkimuksen näkökulmia yhdistävän kurssin, jonka idea syntyi osana yliopistossa käynnissä ollutta Let's work together -toimintaa (letsworktogetheredu.wordpress.com)
Sen tavoite on kehittää keinoja tukea turvapaikanhakijoiden osallisuutta suomalaisessa yhteiskunnassa ja koulutusjärjestelmässä. Yksi konkreettinen toiminnan muoto on ollut turvapaikanhakijoiden ottaminen mukaan sellaisille yliopiston kursseille, jotka sopivat heidän kiinnostuksensa kohteisin ja tarpeisiinsa.

Useimpien yliopistojen strategioissa puhutaan muuttuvasta työelämästä ja korostetaan kansainvälisyyttä, ja nämä teemat olivat myös kurssimme ytimessä. Halusimme lähestyä niitä kokemuspohjaisesti ja kriittisesti. Kehittämisen kohteena ollut kurssi on nimeltään Education, Work and Culture, ja se on osa kasvatustieteiden tutkinto-ohjelman aikuis- ja ammattikasvatuksen opintosuunnan syventäviä opintoja.

Keväällä 2017 kurssia tarjottiin lisäksi sosiaalityön ja suomen kielen opiskelijoille, jotka saattoivat käyttää kurssisuoritusta tutkinto-ohjelmansa valinnaisten opintojen osana. Mukaan rekrytoitiin kurssin teemoista kiinnostuneita turvapaikanhakijoita.

Tavoite oli rakentaa pakolaisuuden ja maahanmuuton teoreettisia ja ammattikäytännöllisiä kysymyksiä eri tieteenalojen näkökulmasta tarkasteleva kurssi: kysymyksiä lähestyttiin sosiaalista, koulutuksellista, ammatillista ja kielellistä osallisuutta yhdistävistä näkökulmista. Kurssin opetus- ja oppimisfilosofia pohjasi dialogiseen näkökulmaan vuorovaikutuksesta ja oppimisesta (Bahtin 1991; Salo 2009; Arnkil \& Seikkula 2014), ja siinä lähdettiin ajatuksesta, että monitieteellisen ja -ammatillisen asiantuntijuuden kehittyminen edellyttää jaettua kokeilevaa ja kokemuksellista oppimisprosessia (Gallagher 2005; Fuchs 2017).

Tiedollinen tavoite oli kyseenalaistaa valtavirtadiskursseja työelämän muutoksesta ja monikult- tuuristumisesta ja altistaa opiskelijat tiedollisesti, emotionaalisesti ja eettisesti mainittujen ilmiöiden ja käsitteiden pulmallisuudelle. Kurssilla käsiteltiin osallisuuden ja osallistumisen rajoja ja kriteerejä: Ketkä kelpaavat monikulttuurisuusdiskurssien ja -käytänteiden piiriin, ketkä jäävät ulkopuolelle? Miksi näin tapahtuu?

Taidollinen tavoite oli oppia työskentelemään monitieteisessä ja kulttuurisesti moninaisessa ryhmässä sekä kohdata osallistavaa työtä tekeviä ihmisiä, perehtyä heidän työhönsä ja ymmärtää heidän ammatillisia haasteitaan. Kurssilaiset tekivät kokeiluja yhteistyössä näiden ihmisten kanssa ja saivat näin mahdollisuuden kokea osallistavan työn ja oman tulevan ammattilaisuuden haasteita. Asenteellis-emotionaalinen tavoite oli lisätä ymmärrystä dialogisesta näkökulmasta yhteistyöhön. Eettinen tavoite oli tukea opiskelijoiden pohdintaa omist asenteistaan suomalaisen yhteiskunnan moninaistumista ja eriarvoistumista kohtaan.

Kurssi koostui viidestä neljän tunnin kontaktiopetuskerrasta ja kenttätyöstä, joka tehtiin pienryhmissä. Kenttätyön tavoite oli tutustua turvapaikanhakija- ja pakolaistyössä mukana olevaan koulutusorganisaatioon, vapaan sivistystyön organisaatioon, järjestöön tai yritykseen sekä kohdata osallistavaa työtä tekeviä ihmisiä ja heidän ammatillisia haasteitaan.

Kenttätyötä tuettiin kurssin kontaktiopetuskerroilla keskusteluissa. Ne pohjasivat kurssin teemoja kasvatustieteen, sosiaalityön ja kielitieteen näkökulmasta tarkastelevien tutkimusartikkeleiden lukemiseen. Lisäksi kukin osallistuja piti kurssin ajan oma oppimispäiväkirjaa ja kirjoitti lopuksi raportin kurssista ja omasta oppimisprosessistaan. Tärkeä osa kurssia olivat Moodle-alustalla käydyt keskustelut.

Kontaktiopetuksen kieli oli englanti, mutta jotkut opiskelijat kirjoittivat henkilökohtaisen päiväkiriansa suomeksi. Alusta lähtien korostimme, ettra olennaista on tulla ymmärretyksi ja olla vuorovaikutuksessa. Kehotimme osallistujia käyttämään niitä kielellisiä resursseja, jotka olivat heille yhteisiä ja kussakin tilanteessa tarkoituksenmukaisia. Pyysimme kurssilaisilta luvan käyttää heidän päiväkirjojaan ja muita tuotoksiaan tutkimusaineiston 


\section{KOKEMUS KULTTUURISESTI} MONINAISESTA RYHMÄSTÄ OLI TÄRKEÄ.

tutkimuksessa, jossa tarkastelemme yliopiston roolia ja vastuuta pakolaisongelmien kohtaamisessa ja ratkaisemisessa.

Kurssille osallistui 25 opiskelijaa, ja ryhmä oli hyvin heterogeeninen. Suomenkielisten tutkinto-ohjelmaopiskelijoiden lisäksi mukana oli useita vaihtoopiskelijoita, kansainvälisiä maisteriopintoja suorittavia opiskelijoita ja turvapaikanhakijoita. Opettajia oli kolme: pääopettajana toimi kasvatustieteiden professori Anja Heikkinen, joka oli toteuttanut samantyyppisiä kursseja aiemminkin. Yhteistyö sosiaalityön yliopistonlehtori Anna Metterin ja suomen kielen yliopistonlehtori Niina Liljan kanssa toi kurssille monitieteistä näkökulmaa.

\section{KURSSIN ETENEMINEN: OMISTA ASENTEISTA}

\section{KRIITTISEEN REFLEKTIOON}

Ensimmäisen kurssitapaamisen tavoite oli luoda opiskelijoista kenttätyöryhmät, saada ryhmien työskentely käyntiin ja johdatella opiskelijat kurssin keskeisten teemojen pohdintaan. Kenttätyöryhmät jaettiin niin, että jokaiseen ryhmään tuli osallistujia eri tieteenaloilta sekä turvapaikanhakijataustainen osallistuja.

Keskustelu kurssin teemoista aloitettiin kulttuuripelillä. Sitä ohjasi turvapaikanhakijana kurssille osallistunut opiskelija, jonka kanssa oli etukäteen sovittu tehtävästä. Peliä pelataan pienissä ryhmissä ja se rakentuu kulttuurikorttien ympärille: kortteihin on painettu eri kulttuureja koskevia väittämiä. Kukin ryhmäläinen vuorollaan nostaa kortin ja lukee siinä esitetyn väittämän, minkä jälkeen ryhmäläiset keskustelevat omista käsityksistään ja asenteistaan väittämää kohtaan.

Peli johdatteli hyvin kurssin teemoihin. Erityisen kiinnostavan siitä teki se, että väittämät koskivat kulttuureja, joita kurssilaiset itse edustivat. Tämä näkyy seuraavassa kurssilaisen oppimispäiväkirjasta poimitussa esimerkissä:

"Meidän ryhmämme ei ehtinyt käsitellä kuin muutaman kysymyksen, sillä keskustelu oli niin vilkasta, varsinkin kun ryhmässä oli kysymyksia koskevien kulttuurien edustajia. Keskustelimme pitkään mm. naisten asemasta Irakissa ja saimm kysymykseen kokemusperäisiä vastauksia ryhmäämme kuuluvalta irakilaiselta naispuoliselt turvapaikanhakijalta."

Ensimmäisellä kerralla opettajat alustivat lisäksi dialogisuudesta. Seuraavat kokoontumiskerra rakentuivat luettujen tekstien ja käynnissä olevan kenttätyön ympärille. Tekstejä käsiteltiin opettajien alustusten pohjalta ja yhdessä keskustellen, ja niiden teemoja nivottiin osaksi käynnissä olevaa työtä.

Jokaisella kokoontumiskerralla kenttätyöryhmät kertoivat lisäksi hankkeensa vaiheesta ja kokemuksistaan, ja ratkaisuja mahdollisesti hankaliin tilanteisiin ideoitiin yhdessä. Kurssin päätöstilaisuuteen kutsuttiin mukaan kaikki yhteistyökumppanit, eli eri organisaatioiden ja yritysten edustajat. Paikalle tuli kuitenkin vain muutama. Opiskelijat pitivät päätöstilaisuudess ryhmittäin esitelmät kenttätyönsä kulusta ja tuloksista.

\section{ONNISTUMISIA JA KEHITTÄMISEN KOHTEITA}

Oppimispäiväkirjat osoittavat, että kokemus kulttuurisesti moninaisessa ryhmässä toimimisesta ja yhdessä tekemisestä oli tärkeä. Alun perin englanniksi kirjoitetut sitaatit ovat loppuviitteissä ${ }^{1}$.

"Minusta tuntuu että tämäntyyppisten asioiden oppiminen olisi mahdotonta vain istumalla ja luentoja kuuntelemalla."

"Kirjoittaessani tätä oppimispäiväkirjaa oivalsin miten helppo on ollut kirjoittaa tällä kurssilla oppimistani asioista. Olen kirjoittanut melko moni oppimispäiväkirjoja opintojeni aikana ja yleens niiden kirjoittaminen on tuntunut vaikealta. Nyt olen huomannut, että oppimispäiväkirjan kirjoittaminen ei ole niin vaikeaa, jos olet kokenut oppimistavoitteet itse.
OPISKELIJOIDEN

KOKEMUKSISSA KOHTAAMISET

OLIVAT MERKITYKSELLISIÄ.

Kokemuksen kautta oppiminen oli kurssin tavoite. Tästä syystä meille opettajille oli palkitsevaa huomata, että myös opiskelijat olivat pitäneet yhdessä tekemistä hyödyllisenä. Heidän teksteissään korostui opiskelijaryhmän taustojen erilaisuuden merkitys. Tekeminen oli ollut mielekästä ja opettavaista erityisesti, koska yhteistyössä tarjoutui paljon mahdollisuuksia oppia toisten taustoista ja kokemuksista, mikä käy ilmi seuraavista aineistonäytteistä:

"Kurssin avauspäivänä näin todellakin ympärilläni huomattavan märän ei-suomalaisia opiskelijoita; ei ainoastaan vaihto-opiskelijoita vaan panin merkille, että monet heistä olivat Irakista Iranista tai Somaliasta. Ollakseni rehellinen ajat telin aluksi, että se oli outoa mutta sitten vaihe vaiheelta tavallaan ymmärsin tällaisen ison ja erilaisista ihmisistä koostuvan ryhmän tarkoituksen. Ymmärsin, että minulla oli suuri mahdollisuus ja todellakin luentojen aika jaoimme tarinoita, tunteita ja kokemuksiamme Suomessa muunmaalaisena ja opimme toisiltamme. Oli todellekin ihmeellistä ajatella, miten monia asioita jaoimme vain neliän tunnin luennon aikana"

Oli hienoa saada yhteys eri taustoista ja opintoaloilta tuleviin ihmisiin. Uskon vahvasti että vuorovaikutus opettajien, sosiaalityöntekijöiden, pakolaisten ja oppimisprosessien opiskelijoiden kanssa niin monen viikon ajan auttoi minua ymmärtämään opettamisen ja oppimisen kysymyksiä paremmin ja rohkaisi ajattelemaan enemmän kuin normaali luento olisi tehnyt. [--] Koin hyvin arvokkaana sen, että opin lisää pakolaisten yksilöllisistä tarinoista. Ajattelen, että vien nämä näkökulmat ja reflektiot mukanani tulevaisuuteen ja voin ehkä käyttää niitä omalla opiskelualallani, opiskelen kansanterveystiedettä.'
Taustoiltaan moninaisessa ryhmässä toimiminen ol monelle uutta. Eniten oppimispäiväkirjoissa reflektoitiinkin juuri ryhmän moninaisuutta ja sen myöt lisääntynyttä ymmärrystä ja oppimista. Päiväkirjojen lähiluvun perusteella kurssin taidolliset, asenteellisemotionaaliset ja eettiset tavoitteet toteutuivat erinomaisesti, ja tässä suhteessa kurssi onnistui hyvin

Kurssin tiedollisia tavoitteita pyrimme saavuttamaan luetuttamalla osallistujilla eri tieteenalojen tekstejä ja keskustelemalla niistä tapaamisissa. Opettajina myös aina johdattelimme keskusteluun kustakin tekstistä nostamalla siitä esiin keskeisiä kysymyksiä ja selittämällä sellaisia keskeisiä termejä, joiden ymmärtäminen oli tärkeää tekstin argumentaation ymmärtämiseksi.

Muiden kuin oman opiskelualan tekstien lukeminen oli opiskelijoista haastavaa. Oppimispäiväkirjoista näkyy, että aina artikkeleiden teemojen reflektoinnissa ei päästy kovin syvälliselle tasolle, eivätkä valitsemamme artikkelit välttämä̈ttä tukeneet projektiryhmien reflektiota tavoitteen tavalla. Se näkyy esimerkiksi seuraavassa aineisto-otteessa:

"Kurssin projektityö tarjosi mahdollisuuden tutkiskella omaa moraalia ja etiikkaa ja oman toiminnan rajoja. Pidin kurssin uudesta, kentän kanss toimivasta lähestymistavasta. Ryhmätyö taas tarjosi mielenkiintoisia keskusteluja. Toisaalta kurssia olisi voinut kehittää syventämällä monitieteistä lähestymistapaa johdattamalla vielä syvemmin joka tieteenalan keskusteluihin ja käsitteisiin."

Erityisesti kurssin tiedollisia tavoitteita koskevaan osaan osallistujat olisivat toivoneet vielä opettajajohtoisempaa otetta, ja tältä osin kurssia tulee kehit tää edelleen.

\section{YLIOPISTON TEHTĀVÄT}

Suhtautumisemme turvapaikanhakijatilanteesee nostaa näkyväksi jotakin olennaista suomalaisen nyky-yliopiston tilanteesta ja yliopistopedagogisten käsitysten perustasta. Yliopistossa on vallalla vahva uusliberalistinen eetos: jokaisen on jatkuvasti teht vä tulosta annetuilla mittareilla ja osoitettava ansainneensa paikkansa. Kansainvälisyyttä korostetaan, 
mutta se ymmärretään lähinnä liikkuvuudeksi pois Suomesta tai ulkomaalaisten huippututkijoiden houkuttelemiseksi keskuuteemme. Usein unohtuu, etta myös kansainväliset turvapaikanhakijat voisivat tuoda korkeakouluihimme kansainvälisyyttä ja osaamista ja että heidän koulutuspolkuaan olisi tarkoituksenmukaista tukea (ks. myös Heikkinen 2017; Hoffman \& Piepponen 2017; Käyhkö 2017).

Yhteiskunnan eriarvoistuminen näkyy koulujen ja asuinalueiden eriytymisenä, sukupolvelta toiselle periytyvänä työttömyytenä, syrjäytymisenä ja tuloerojen kasvuna (ks. Therborn 2014). Yliopistoilla on tärkeä rooli toiminnassa eriarvoistavaa kehitystä vastaan. Toiminta tarkoittaa tutkimusta kehityskulkujen syistä ja syiden näkyväksi tekemistä, mutt sen tulisi tarkoittaa myös käytännön toimia ja rajojen purkamista.

Pieni askel niin näkyvien kuin näkymättömien rajojen purkamista kohti voi olla se, että annetaan eri taustoista tuleville opiskelijoille mahdollisuus ja paikka kohtaamiseen ja yhteistyöhön, ja näin olemme kurssimme avulla pyrkineet tekemään (ks. myös Heikkinen \& Peltonen 2018.)

Kurssilta saamamme kokemukset ovat rohkaisevia, sillä ne osoittavat, että opiskelijoiden kokemuksissa kohtaamiset ovat olleet merkityksellisiä. Kurssin jälkeen saamamme palaute kertoo, että kohtaamiset ovat synnyttäneet ymmärrystä, joka autta osallistujia toimimaan tulevaisuudessa maailman muuttamiseksi.

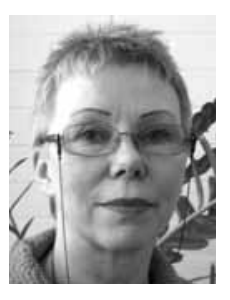

\section{ANJA HEIKKINEN}

$\mathrm{KT}$, FM, kasvatustieteen professori

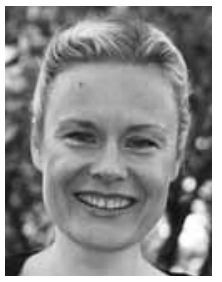

NA LILJA

FT, yliopistonlehtori, suomi toisen

Tampereen yliopisto

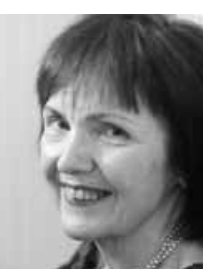

ANNA METTERI

TT, yliopistonlehtori, sosiaalityö

Tampereen yliopisto

kuin ne ovat: things if we only sat and listened to lectures."

"When writing this learning diary I have realized how easy it has been to write about the things I have learned during this course. I have written quite many learning diaries during my studies and usually they have felt difficult to write. Now I have noticed that the learning diary is not that difficult to write, when you have experienced the learning outcomes yourself."

"Indeed, during the opening day of the course I saw around me a very considerable number of non-Finnish students; not only exchange students but also I noticed that many of them were from Iraq Iran or Somalia. To be honest, at the beginning I thought that it was very weird, but then step by step I kind of realize the
Pyykkö, R. (2017). Integration of academic migrants: From problemativ areas towards flexible transitions. Teoksessa Käyhkö, K., Bontenbal, I. \& M. Bogdanoff (toim.) "Open the doors!": Migrants in Higher Education. Fostering cooperation at Universities UniPiD \& Jyäskylän yliopisto, 29-31.

Salo, O.-P. (2009). Dialogisuus kielikasvatuksen kehyksenä. Puhe ja kieli 29 (2), 89-102.

Therborn, G. (2014). Eriarvoisuus tappaa. Tampere: Vastapaino.

Vaarala, H., Haapakangas, E.-L., Kyckling, E. \& T. Saarinen (2017). Finnish higher education institutions' reactions to the 2015 asylum seeker Motives, goals and future challenges. Apples - Journal of Applied Lanquage Studies 11 (3) 143-165. intention of this big mixed class. I understood the big opportunity that I had, in fact during all the lessons we shared stories, feelings, pieces of life in Finland as foreigner and we learned from each other. It was surprisingly amazing thinking of how many things we

"Reflecting on the class it was amazing to get in contact with people from different backgrounds and fields of study. I strongly believe that talking to teachers, social workers, refugees and students about the learning process for so many weeks helped me to understand the issues of learning and teaching way better and encouraged thinking more than a normal class could have. [--] I perceived

learning more about individual stories of refugees as very valuable. I think I will take these insights and reflections with me in my further life and I might be able to use them in my field of study, I study public health.

LÄHTEET

Arnkil, T. E. \& J. Seikkula (2014). "Nehän kuuntell meitä!": Dialogeja monissa suhteissa. Helsink: Terveyden ja hyvinvoinnin laitos.

Bahtin, M. (1991). Dostojevskin poetiikan ongelmia. Helsinki: Orient Express.

Fuchs, T. (2017). Collective Body Memories. Teoksessa C. Durt, T. Fuchs, C. Tewes (toim.) Embodiment, Enaction and Culture. Cambridge/Mass: MIT Press. Gallagher, S. (2005). How the Body Shapes the Mind. Oxford: Oxford University Press.
Heikkinen, A. (2017). Sharing and Caring. Teoksessa Käyhkö, K., Bontenbal, I. \& M. Bogdanoff (toim.) "Open the doors!": Migrants in Higher Education Fostering cooperation at Universities Seminar 13.-14.12.2016 in Jyväskylä. Jyväskylä: UniPiD \& Jyväskylän yliopisto, 25-26.

Heikkinen, A. \& Peltonen, S. (2018). Ylikansallisen liikkuvuuden ja superdiversiteetin paradoksit yliopiston reaktioita "pakolaiskriisiin". Haltia, N. ym. (toim.). Eriarvoistuva maailma - tasa-arvoistava koulu? Jyväskylä: Research in Educational Sciences. 